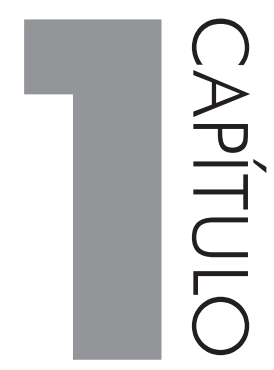

\title{
INSPIRAÇÃO PARA A INOVAÇÃO NA EDUCAÇÃO
}

\section{RAYSE KIANE DE SOUZA, CLARISSA STEFANI TEIXEIRA, MÁRCIO VIEIRA DE SOUZA}

\section{INTRODUÇÃO}

As inovações estão por todas as partes, em todos os segmentos e aspectos da vida. Inovar significa fazer algo novo ou significativamente melhorado que gere valor (Manual de Oslo, 2005). O contexto econômico demonstra que as nações mais inovadoras são as mais competitivas (World Economic Forum, 2016). Além disso, cada vez mais se observa a necessidade de inovadores para o mundo do trabalho e, consequentemente, empresas buscam por competências que se associam a nova sociedade do conhecimento. As problemáticas hoje se relacionam em como impulsionar essas competências, desde crianças, para uma vida adulta de talento criativo e inovador.

Como exemplo destas questões, autores como Teixeira, Calegari, Dellagnello, Gonçalves \& Kotujansky (2015) indicam que a educação brasileira, diferente de outros países, ainda não se estrutura de forma articulada para alcançar índices de competitividade global. Mesmo que exista consenso sobre a importância de se oferecer aos estudantes uma boa formação educacional e o quanto a tecnologia colabora nesta direção, as empresas ainda despendem esforços individuais de desenvolvimento, marketing, comercialização e formação para alcançar os níveis desejados de inovação e criatividade. 
Baseando nessas premissas e estando na era do compartilhamento de conhecimento, uma das ações que vem sendo realizada, por diferentes autores e entidades, é explicitar as inovações realizadas em sala de aula, de forma a inspirar outros professores. Ainda é foco de análise pelo Centro de Pesquisa e Inovação Educacional (Centre for Educational Research and Innovation - CERI) da OECD como a inovação na educação pode ser incentivada e efetivamente colocada em prática. Nessa mesma preocupação, pergunta-se como está sendo realizada a contribuição do capital humano para a inovação (Ischinger, 2010).

Entretanto, ainda faltam estudos que busquem compilar esses dados de forma a mostrar o panorama inovador de escolas e professores, inclusive as iniciativas nacionais realizadas. Assim, o presente estudo busca demonstrar as estratégias realizadas por professores e instituições com foco em inovação em sala de aula ou nas escolas de forma a inspirar novos professores a terem práticas diferentes com seus alunos.

\section{O CONCEITO DE INOVAÇÃO NA EDUCAÇÃO}

Mesmo que o mundo corporativo venha discutindo o conceito de inovação, suas aplicações, desenvolvimentos e impactos, é importante que os conceitos sejam focados nos diferentes contextos. Assim, especificamente na educação, pode-se dizer que as inovações educacionais dependem de diversos fatores, mas, sobretudo, do contexto, dos padrões culturais, do campo de conhecimento e da visão de educação dos atores do processo (Nunes, Nakayama, Silveira, Stefani \& Calegari, 2015). De maneira geral, Ortega et al. (2007) indicam que não existe um único modelo ou tipo de inovação educacional, e sim inovações educacionais determinadas pelo contexto e pela cultura.

A inovação não pode ser considerada como sinônimo de invenção ou ainda de implantação ou uso da tecnologia. O conceito está mais associado à inserção de algo novo em uma dada situação. Além disso, para Ortega et al. (2007) a inovação deve promover uma melhoria real e efetiva em uma determinada conjuntura. Os mesmos autores entendem ainda que a inovação é uma maneira diferente de configurar e ligar os elementos que constituem o objeto da inovação, é uma criação em um contexto específico.

Nunes et al. (2015) consideram a definição de inovação educacional uma prática educacional inovadora a ação pedagógica estruturada relativamente nova, que promove melhorias no processo de ensino-aprendizagem, considerando os diferentes contextos escolares, os interesses e necessidades dos alunos.

Os mesmos autores ainda se preocuparam em definir critérios para mensurar a inovação educacional. Após análise de especialistas os critérios para a inovação educacional são critérios essenciais (impacto, contextualização, eficiência, aplicabilidade, engajamento, intencionalidade) e desejáveis (interdisciplinaridade, inter-relacionamento e inclusão), assim como mostra o Quadro 1. 
Quadro 1 Critérios essenciais e desejáveis que todas as práticas devem observar, sua descrição e seus respectivos indicadores.

\begin{tabular}{|c|c|c|}
\hline CRITÉRIO & DESCRIÇÃO & INDICADORES \\
\hline Impacto & $\begin{array}{l}\text { A ação pedagógica inovadora deve gerar mudanças } \\
\text { que resultem em melhorias reais para a educação. } 0 \\
\text { impacto refere-se ao efeito gerado após a execução } \\
\text { da prática educacional inovadora. Este deve ser sig- } \\
\text { nificativo e claramente percebido nos alunos e no seu } \\
\text { desempenho. }\end{array}$ & $\begin{array}{l}\text { - Demonstra resultados substanciais } \\
\text { - de melhoria na aprendizagem. } \\
\text { ciais de melhoria do fluxo escolar. } \\
\text { - Demonstra resultados substan- } \\
\text { ciais no desenvolvimento de com- } \\
\text { petências dos alunos, consideran- } \\
\text { do sua diversidade de interesses e } \\
\text { necessidades. }\end{array}$ \\
\hline Contextualização & $\begin{array}{l}\text { A prática educacional deve ser elaborada e executada } \\
\text { considerando as características do local e das pesso- } \\
\text { as envolvidas no processo. A inovação só apresentará } \\
\text { resultados satisfatórios se estiver contextualizada. A } \\
\text { contextualização é um dos fatores mais determinan- } \\
\text { tes para o êxito de uma prática inovadora, e é um risco } \\
\text { tentar importar práticas sem as devidas adaptações } \\
\text { que respeitem as características culturais, sociais, his- } \\
\text { tórias e econômicas dos alunos e da escola. }\end{array}$ & $\begin{array}{l}\text { - Considera circunstâncias sociais, } \\
\text { econômicas e culturais da escola, } \\
\text { da comunidade e da localidade. }\end{array}$ \\
\hline Eficiência & $\begin{array}{l}\text { A eficiência refere-se à racionalização dos recursos } \\
\text { (materiais, humanos, financeiros), de modo que se } \\
\text { obtenha o melhor resultado possível com a menor } \\
\text { quantidade de recursos. Ser eficiente na prática edu- } \\
\text { cacional inovadora é empregar da melhor forma pos- } \\
\text { sível os recursos disponíveis. }\end{array}$ & $\begin{array}{l}\text { - Fez bom uso dos recursos (mate- } \\
\text { riais e de estrutura) disponíveis. }\end{array}$ \\
\hline Aplicabilidade & $\begin{array}{l}\text { Aplicabilidade é a possibilidade de implementar a } \\
\text { prática em outro contexto fazendo as devidas con- } \\
\text { textualizações. }\end{array}$ & $\begin{array}{l}\text { - É aplicável em outras realidades } \\
\text { educacionais, com as devidas } \\
\text { adaptações. }\end{array}$ \\
\hline Engajamento & $\begin{array}{l}\text { Engajamento na prática educacional inovadora é o en- } \\
\text { volvimento e a interação entre os envolvidos: alunos, } \\
\text { professores, servidores técnico-administrativos e di- } \\
\text { reção da escola. O engajamento se reflete no empenho } \\
\text { com o qual os envolvidos participam da prática. }\end{array}$ & $\begin{array}{l}\text { - Promove o envolvimento ativo de } \\
\text { alunos, professores, gestores e da } \\
\text { comunidade na prática inovadora. }\end{array}$ \\
\hline Intencionalidade & $\begin{array}{l}\text { A inovação não é um fim em si mesma, mas sim uma } \\
\text { forma de alcançar os objetivos da educação. A inovação } \\
\text { educacional deve ser orientada para resultados, promo- } \\
\text { vendo mudanças significativas no contexto pedagógico } \\
\text { e/ou escolar. }\end{array}$ & $\begin{array}{l}\text { - Soluciona problemas dos alunos, } \\
\text { professores e da escola como um } \\
\text { todo. }\end{array}$ \\
\hline
\end{tabular}




\begin{tabular}{|l|l|l|l|}
\hline $\begin{array}{l}\text { Interdisciplina- } \\
\text { ridade }\end{array}$ & $\begin{array}{l}\text { Na prática educacional inovadora a interdisciplinari- } \\
\text { dade pode estar presente na busca por integração } \\
\text { entre diferentes disciplinas, conteúdos e abordagens. }\end{array}$ & $\begin{array}{l}\text { Integra diferentes conteúdos, disci- } \\
\text { plinas e/ou áreas de conhecimento. } \\
\text { Traz elementos novos gerando no- } \\
\text { vas formas de aprender e de ensinar. }\end{array}$ \\
\hline \multirow{2}{*}{$\begin{array}{l}\text { Inter-relaciona- } \\
\text { mentos }\end{array}$} & $\begin{array}{l}\text { A diversidade de pessoas de fora da escola envolvidas } \\
\text { na prática inovadora é altamente enriquecedora. A in- } \\
\text { clusão de colaboradores e organizações além da escola } \\
\text { aumenta a complexidade da prática, pois há potencial- } \\
\text { mente mais conflitos e mais pessoas para gerenciar, } \\
\text { porém incrementa a capacidade da rede para resolver } \\
\text { problemas multidimensionais, que não podem ser re- } \\
\text { duzidos às perspectivas particulares de indivíduos. }\end{array}$ & $\begin{array}{r}\text { Promove a participação de ato- } \\
\text { res externos à escola, formando } \\
\text { parcerias com outros professores, } \\
\text { escolas, comunidade ou outras or- } \\
\text { ganizações. }\end{array}$ \\
\hline Inclusão & $\begin{array}{l}\text { A inclusão em práticas educacionais inovadoras re- } \\
\text { fere-se ao acolhimento de todos os alunos, indepen- } \\
\text { dentemente de cor, classe social e condições físicas } \\
\text { e psicológicas. }\end{array}$ & $\begin{array}{c}\text { Promove a aceitação e a valoriza- } \\
\text { ção das diferenças individuais. }\end{array}$ \\
\hline
\end{tabular}

Fonte: Adaptado de Nunes et al. (2015).

Além disso, o estudo da Fundação Telefônica (2014) fez uma análise da inovação considerando fatores educativos (melhorar a aquisição de competências em STEM), psicológicos (promoção do envolvimento ativo dos alunos no processo de reflexão sobre suas competências e interesses e as concordâncias destes com os requeridos em STEM), informativos (divulga as possibilidades de trabalho no setor técnico-científico) e sociais (melhorar a imagem social das carreiras em STEM), assim como ilustra a Figura 1.

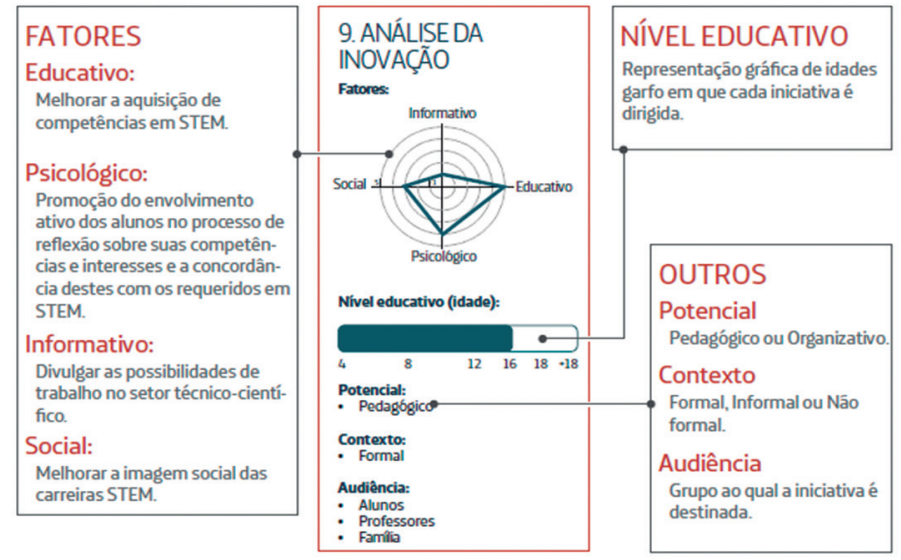

Figura 1 Análise da inovação no âmbito das práticas educativas.

Fonte: Fundação Telefônica (2014, p. 5). 
A inovação é possível de ser realizada em âmbito escolar ou ainda nos contextos informais e não formais. Entretanto, ela precisa gerar valor para alunos, professores e família. Gravatá, Mayumi \& Shimahara (2013) consideram que:

... a inovação em educação demanda não apenas observar o contexto, valorizar o aluno e, claro, cada uma das pessoas envolvidas, mas também aceitar os riscos atrelados à mudança. A mudança não é indolor, simples e rápida. Mudanças genuínas exigem maturação, demandam que as pessoas sustentem a vontade de mudar por bastante tempo.

\section{AS PRÁTICAS INOVADORAS NA EDUCAÇÃO: DISSEMINAÇÃO PARA A INSPIRAÇÃO EM INOVAR}

Em termos de disseminação do conhecimento, diferentes são as estratégias que vêm sendo realizadas para demonstrar o que escolas e professores estão desenvolvendo em âmbito escolar. As iniciativas se centralizam principalmente em entidades não governamentais e atores que por meio de seus documentos buscam demonstrar as boas práticas.

A exemplo dessas informações, cita-se a Fundação Telefônica que vem constantemente elaborando documentos que mostram as oportunidades de se trabalhar de forma diferente em sala de aula. Com objetivo de gerar oportunidades para que se difundam as iniciativas educativas que demonstraram ser mais eficazes e, portanto, mais inovadoras, a fim de estimular a aprendizagem foi lançado o documento Top-100 Inovações Educativas. Neste documento é possível identificar os resultados do projeto Desafio Educação, realizado ao longo de 2014 para identificar iniciativas educativas inovadoras, isto é, inovadoras, mas com resultados comprovados, no âmbito do ensino das ciências em sentido amplo. As iniciativas consideradas com maior potencial de desenvolvimento são apresentadas de forma a permitir a disseminação do conhecimento que tem valor para toda a comunidade educativa e a sociedade em geral (Fundação Telefônica, 2014).

Rangel et al. (2013) lançaram no contexto do livro Cultura digital e educação: novos caminhos e novas aprendizagens "Casos: Aprendizagens para além da escola", neste documento, fomentado pela Fundação Telefônica VIVO Brasil, nove reportagens contam as histórias que movimentaram ao longo de 2012 educadores, crianças, jovens, brincantes, gamers, mestres da cultura popular, artistas digitais e cineastas em projetos de exploração das tecnologias de informação e comunicação.

Gravatá et al. (2013) apresentaram práticas realizadas em 13 escolas do mundo. O livro apresenta o que de mais inspirador foi encontrado pelo caminho percorrido. 
Mais recentemente o Porvir ${ }^{1}$ e o Instituto Brasileiro de Formação de Professores (IBFE) lançam chamada para conhecimento das práticas inovadoras e compilam em um documento o que vem sendo realizado pelos professores brasileiros. O Desafio Diários de Inovações apresenta 16 práticas para que professores possam inovar na sala de aula. O livro tem objetivo de entender o que os profissionais da educação estão fazendo para transformar suas práticas pedagógicas e tornar a experiência educacional de crianças, adolescentes, jovens e adultos mais significativa e conectada com a realidade atual. Assim, boas práticas na educação infantil, ensino fundamental I e II, ensino médio, Educação de Jovens e Adultos (EJA) e ensino superior podem ser encontradas. A experiência das ações é relatada junto com dicas de número de alunos envolvidos, tempo de aplicação, ferramentas de engajamento, competências a serem desenvolvidas e recursos. Demonstração de como fazer, nas fases de preparação, aplicação e identificação de fatores críticos para o sucesso também podem ser observados.

Além disso, 150 práticas inovadoras enviadas por professores de todo o Brasil podem ser encontradas no mapa ${ }^{2}$ de professores Diário de Inovações 2018, assim como ilustra a Figura 2.

No mapa é possível identificar os dados dos professores, instituição e etapa escolar além do local onde a mesma é aplicada. Ademais, é possível acessar a descrição da prática, recomendar e escrever comentários sobre a mesma.

O governo também vem agindo como fomentador das práticas inovadoras dentro das escolas. Não apenas com os portais já conhecidos do Ministério da Educação, como o Portal do Professor, onde os professores podem compartilhar suas práticas e ainda se inspirar em documentos de colegas, há plataformas que incentivam o uso de materiais didáticos em sala de aula como o MECFlix ${ }^{3}$, TV Escola $^{4}$ e o Banco Internacional de Objetos Educacionais ${ }^{5}$ (BIOE).

1 Porvir é “uma iniciativa de comunicação e mobilização social que mapeia, produz, difunde e compartilha referências sobre inovações educacionais para inspirar melhorias na qualidade da educação brasileira e incentivar a mídia e a sociedade a compreender e demandar inovações educacionais" (PORVIR, 2018).

2 Mapa de professores Diário de Inovações 2018 - Porvir. Disponível em: <https://goo.gl/mheP5B>.

3 MECFlix: plataforma de estudos com vídeo aulas oferecidas sem custos por parceiros selecionados do MEC. Disponível em:<http://mecflix.mec.gov.br/>.

4 TV Escola: plataforma de comunicação baseada em televisão e internet do MEC. Disponível em: <https://tvescola.org.br/tve/home>.

5 BIOE: Repositório de objetos educacionais de acesso público. Disponível em: <http://objetoseducacionais2.mec.gov.br/>. 


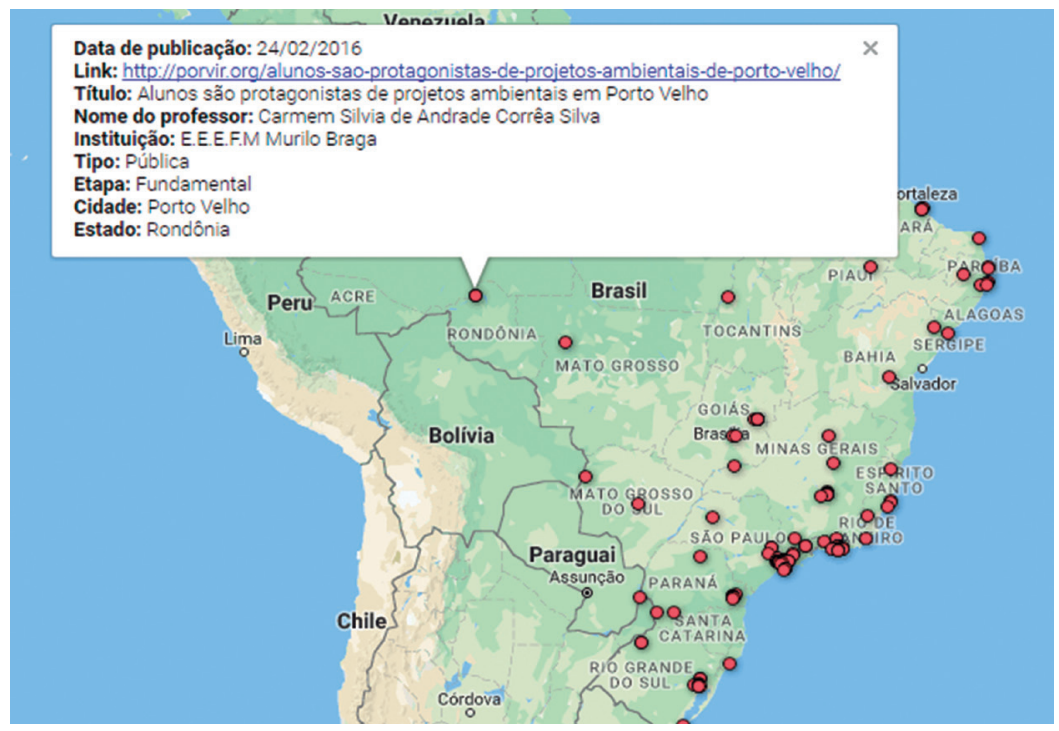

Figura 2 Mapa de professores Diário de Inovações, 2018.

Fonte: Porvir (2018). Disponivel em: <https://goo.gl/mheP5B>.

De forma a demonstrar o que é produzido nos municípios brasileiros, concursos são realizados para premiar os professores. Como exemplo desses incentivos, citam-se o Projeto Professor Nota 10: aprendendo a ensinar melhor, o Olimpíada da língua portuguesa: escrevendo o futuro, o Jovens Embaixadores e o Prêmio Professores do Brasil, assim como mostra o Quadro 2.

Quadro 2 Projetos realizados em âmbito nacional para identificar professores e práticas inovadoras no Brasil.

\begin{tabular}{|l|l|l|}
\hline \multicolumn{1}{|c|}{ PROJETOS } & \multicolumn{1}{|c|}{ DESCRIÇÃo GERAL } & \multicolumn{1}{|c|}{ ANOS DE REALIZAÇÃO E PÁGINA } \\
\hline \multirow{2}{*}{$\begin{array}{l}\text { Projeto Professor } \\
\text { Nota 10: apren- } \\
\text { dendo a ensinar } \\
\text { melhor }\end{array}$} & $\begin{array}{l}\text { Instituído pela Lei }{ }^{6} \text { n. 8.024, de 26 de outubro } \\
\text { de } 2009 \text { no município de Florianópolis - SC aos } \\
\text { professores da Rede Municipal de Ensino que } \\
\text { mais se destacarem pelo trabalho inovador, cria- } \\
\text { tivo e transformador. }\end{array}$ & $\begin{array}{l}\text { Todo ano a partir de } 2009 \text { conforme } \\
\text { previsão da Lei. }\end{array}$ \\
$\begin{array}{l}\text { Página: } \\
\text { <http://www.pmf.sc.gov.br/entidades/ } \\
\text { educa/?cms=vi+edicao+do+premio+pr } \\
\text { ofessor+nota+10> }\end{array}$ \\
\hline
\end{tabular}

6 Lei n. 8.024, de 26 de outubro de 2009. Disponível em: <http://www.pmf.sc.gov.br/ entidades/educa/?cms=vi+edicao+do+premio+professor+nota+10>. Acesso em: 19 jan. 2018 


\begin{tabular}{|c|c|c|}
\hline $\begin{array}{l}\text { Olimpíada de língua } \\
\text { portuguesa: escre- } \\
\text { vendo o futuro }\end{array}$ & $\begin{array}{l}\text { A Olimpíada de Língua Portuguesa Escrevendo } \\
\text { o Futuro é um concurso de produção de textos } \\
\text { para alunos de escolas públicas de todo o país, } \\
\text { do } 5^{\circ} \text { ano do Ensino Fundamental ao } 3^{\circ} \text { ano do } \\
\text { Ensino Médio. Iniciativa do Ministério da Educa- } \\
\text { ção e da Fundação Itaú Social, com coordenação } \\
\text { técnica do Centro de Estudos e Pesquisas em } \\
\text { Educação, Cultura e Ação Comunitária (Cenpec) } \\
\text { (Escrevendo o Futuro, 2018). }\end{array}$ & $\begin{array}{l}\text { Anos de realização: } \\
2014 \text { e } 2016 . \\
\text { Página: } \\
\text { <https://www.escrevendoofuturo.org. } \\
\text { br/> }\end{array}$ \\
\hline $\begin{array}{l}\text { Jovens Embai- } \\
\text { xadores }\end{array}$ & $\begin{array}{l}\text { O programa tem como alvo alunos brasileiros } \\
\text { que são exemplos em suas comunidades, em } \\
\text { termos de liderança, atitude positiva, trabalho } \\
\text { voluntário, excelência acadêmica e conheci- } \\
\text { mento da língua inglesa. O programa visa forta- } \\
\text { lecer o ensino público por meio desses alunos, } \\
\text { transformando-os em modelos para as suas } \\
\text { comunidades (US Embassy, 2018). }\end{array}$ & $\begin{array}{l}\text { Anos de realização: } \\
2002 \text { a } 2017 . \\
\text { Página: } \\
\text { <https://br.usembassy.gov/pt/edu- } \\
\text { cation-culture-pt/programa-jovens- } \\
\text {-embaixadores/sobre-o-programa/> }\end{array}$ \\
\hline $\begin{array}{l}\text { Prêmio Profes- } \\
\text { sores do Brasil }\end{array}$ & $\begin{array}{l}\text { O Prêmio Professores do Brasil é uma iniciati- } \\
\text { va do Ministério da Educação juntamente com } \\
\text { instituições parceiras que busca reconhecer, } \\
\text { divulgar e premiar o trabalho de professores } \\
\text { de escolas públicas que contribuem para a me- } \\
\text { Ihoria dos processos de ensino e aprendizagem } \\
\text { desenvolvidos nas salas de aula (Prêmio Pro- } \\
\text { fessores do Brasil, 2018). }\end{array}$ & $\begin{array}{l}\text { Anos de realização: } \\
\text { 2005, 2007, 2008, 2009, 2011, 2012, } \\
\text { 2013, 2014, 2015 e } 2017 . \\
\text { Página: } \\
\text { <http://premioprofessoresdobrasil. } \\
\text { mec.gov.br/> }\end{array}$ \\
\hline
\end{tabular}

Fonte: Elaborado pelos autores.

Como forma de dar maior visibilidade dos professores nesses concursos, o Estado de Santa Catarina, por meio do Movimento Educação Fora da Caixa, realizado por diversas entidades do ecossistema de inovação na educação (Teixeira et al., 2017), criou um mapeamento georeferenciado indicando as práticas realizadas pelos professores catarinenses nos respectivos concursos. Essas práticas podem ser visualizadas na Figura 3.

A partir das práticas apresentadas por diferentes entidades, e com o fomento do governo em premiar os inovadores e criativos mostrando as práticas para outros professores, é possível inspirar novos docentes na tentativa de disseminar a inovação a educação. 


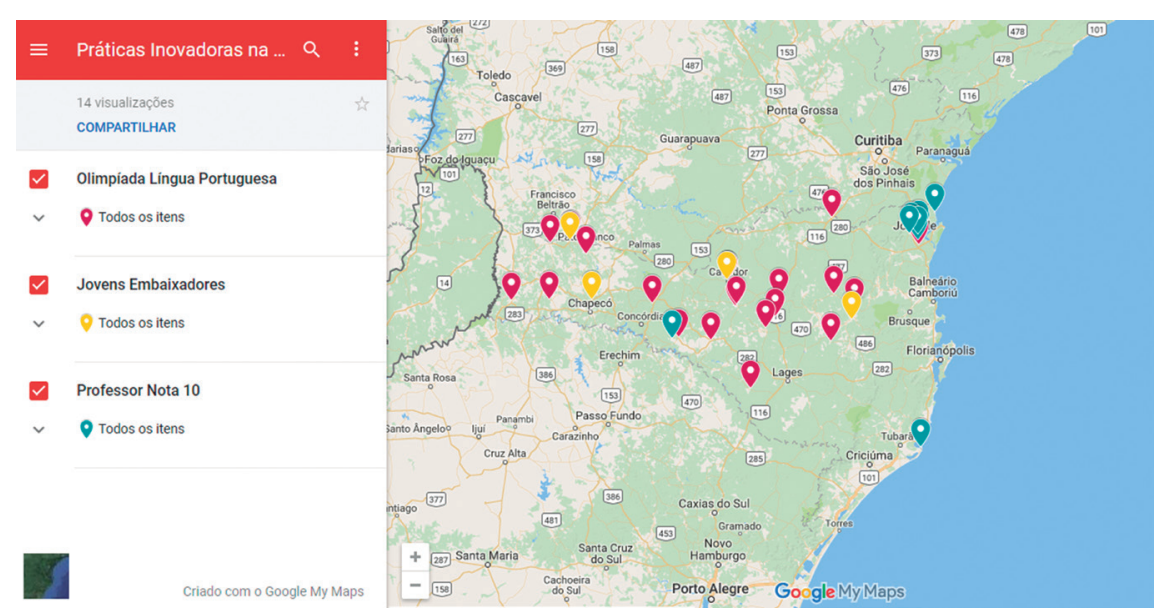

Figura 3 Boas práticas em Santa Catarina.

Fonte: Disponível em: <https://goo.gl/caQQw2>.

\section{CONSIDERAÇÕES FINAIS}

"Nós acreditamos no potencial da educação para redescobrir a felicidade e exercitar a capacidade de sonhar” (Gravatá et al., 2013).

As iniciativas encontradas permitem a replicabilidade de diversas ações, para idades e áreas diferentes. As práticas relatadas são sistematizadas para que professores possam ser inspirados em serem agentes da inovação. Os insigths para que as inovações em sala de aula ou ainda fora dela existem e diversas entidades fazem esforços de demonstrar como estas podem ser implantadas para o efetivo sucesso. Algumas delas são relatadas inclusive os fatores críticos para a implementação.

As boas práticas foram mostradas e impulsionadas pelas diferentes entidades, mesmo assim ainda falta realizar a expansão das mesmas em larga escala. Embora diversos professores sejam proativos e venham compartilhando suas realizações, ainda é necessário identificar em um contexto maior como estas estão sendo incorporadas.

\section{REFERÊNCIAS}

Escrevendo o Futuro. (2018). Olimpiada de Lingua Portuguesa Escrevendo o Futuro. Consultado em: 14 de janeiro de 2018. Disponível em: <https://www.escrevendoofuturo. org.br/concurso>.

Fundação Telefônica. (2014). Top 100 Inovações Educativas. Consultado em 14 de janeiro (2018). Disponível em: <http://fundacaotelefonica.org.br/wp-content/uploads/pdfs// top100_pt.pdf>. 
Gravatá, A. Piza, C., Mayumi, C. \& Shimahara, E. (2013). Volta ao mundo em 13 escolas. São Paulo: Fundação Telefônica. Disponível em: <http://educacaosec21.org.br/wpcontent/uploads/2013/10/131015_Volta_ao_mundo_em_13_escolas.pdf>. Acesso em: 14 janeiro de 2018.

Ischinger, B. (2010). Inspirados pela tecnologia, norteados pela pedagogia: uma abordagem sistêmica das inovações educacionais de base tecnológica. Centro de Pesquisas Educacionais e Inovação - OCDE e Governo do Estado de Santa Catarina.

Manual de Oslo (2005). Diretrizes para coleta e interpretação de dados sobre inovação, 3. ed. Brasília: OECD/FINEP.

Nunes, C. S., Nakayama, M., Silveira, R. A., Stefani, C. \& Calegari, D. (2015). Critérios e indicadores de inovação na educação. In: Teixeira, C. St.; Ehlers, A. C.; Souza, M. V. Educação fora da caixa: Tendência para a educação no século XXI. Florianópolis: Bookess, 2015. p. 49-60. Disponível em: <http://eduforadacaixa.com.br/principal/wp-content/uploads/2015/09/eBook-Educa\%C3\%A7\%C3\%A3o-fora-da-caixa.pdf>.

Ortega Cuenca, P., Ramírez Solís, M., Torres Guerrero, J., López Rayón, A., Servín Martínez, C., Suárez Téllez, L. et al. (2007). Modelo de innovación educativa. Un marco para la formación y el desarrollo de una cultura de la innovación. RIED. Revista iberoamericana de educación a distancia, v. 10, n. 1.

Prêmio Professores do Brasil (2018). Prêmio Professores do Brasil. Consultado em: 14 de janeiro. Disponível em: <http://premioprofessoresdobrasil.mec.gov.br/>.

Porvir (2018). Porvir. Consultado em 14 janeiro de 2018. Disponível em: <http://porvir. org/>. Acesso em: 14 janeiro de 2018.

Rangel, L. et al. (2013). Cultura digital e educação: novos caminhos e novas aprendizagens. São Paulo: Fundação Telefônica Vivo, 2013. Disponível em: <http://fundacaotelefonica.org.br/wp-content/uploads/pdfs/cultura-digital-e-educacao.pdf>.

Teixeira, C. S., Calegari, D., Dellagnelo, L. G. V., Gonçalves, R. L. \& Kotujansky, S. (2015). Cluster de Inovação na Educação: Estratégias para a melhoria da educação e competitividade organizacional. In: Teixeira, C. St.; Ehlers, A. C. \& Souza, M. V. Educação fora da caixa: Tendências para a educação no século XXI. Florianópolis: Bookess.

Teixeira, C. S., Ehlers, A. C. da S. T., Calegari, D., Hamad, A., Pinheiro, C. D. B., Lima, C. P. et al. (2017). Ecossistema de Inovação na Educação de Santa Catarina. In: Teixeira, C.; Souza, M. V. Educação Fora da Caixa Tendência para a Educação no Século XXI: perspectivas e reflexões sobre a inovação na educação. Florianópolis: Perse, p. 11-30. Disponível em: <http://eduforadacaixa.com.br/principal/wp-content/uploads/2017/11/ book-eduforadacaixa-vol2-v3.pdf>.

US Embassy. (2018). Programa Jovens Embaixadores. Consultado em: 14 de janeiro. Disponível em: <https://br.usembassy.gov/pt/education-culture-pt/programa-jovens-embaixadores/>.

World Economic Forum (2016). The Global Competitiveness Report 2016-2017. Switzerland: World Economic Forum, 400 p. Consultado em: 31 março de 2017. Disponível em: <http://www3.weforum.org/docs/GCR20162017/05FullReport/TheGlobalCompetitivenessReport2016-2017_FINAL.pdf>. 